\title{
Praia dos Ingleses 1: Arqueologia Subaquática na Ilha de Santa Catarina, Brasil (Parte 2)*
}

\author{
Francisco Silva Noelli** \\ Patrícia Cardoso Monteiro*** \\ Alexandre Viana****
}

NOELLI, F.S.; MONTEIRO, P.C.; VIANA, A. Praia dos Ingleses 1: Arqueologia subaquática na Ilha de Santa Catarina, Brasil (Parte 2). R. Museu Arq. Etn., São Paulo, n. 21, p. 293-314, 2011.

Resumo: Este trabalho é a continuidade do artigo publicado na Revista do Museu de Arqueologia e Etnologia (Noelli, Viana, Moura 2009), onde apresentamos: 1) a metodologia de arqueologia subaquática aplicada na escavação de um naufrágio na Praia dos Ingleses, Ilha de Santa Catarina; 2) os primeiros resultados da análise dos achados; 3) a pesquisa histórica sobre o contexto do naufrágio e da identificação da embarcação. Apresentaremos, agora, os dados que confirmam a hipótese que testávamos em 2009: que o barco pesquisado era aquele que as fontes históricas indicavam ser o liderado por Thomas Frins e mais sete ingleses, acusados de pirataria no Vice-Reino do Peru (1687) e no Brasil (1688).

Palavras-chave: Arqueologia Subaquática - História Marítima - Brasil Colonial.

E ste artigo é a continuidade de outro publicado na Revista do Museu de Arqueologia e Etnologia (Noelli, Viana, Moura 2009), onde apresentamos: 1) a metodologia de arqueologia subaquática aplicada na escavação de um naufrágio na Praia dos Ingleses, Ilha de

(*) Pesquisa realizada pelo PAS - Projeto de Arqueologia Subaquática. Financiado pela Fundação de Apoio à Pesquisa do Estado de Santa Catarina (Convênios 01/2004 e 18.350/2008-4); autorizada pela Marinha do Brasil (Portaria n. 59/DPC, de 03/06/2003 - D.O.U. n. 11, seção 1, p. 7 , de 16/01/2004). Contrato de Autorização (n. 52.000/2003015/00 - DPC/Marinha do Brasil), acordado no dia $16 / 12 / 2003$, entre a autoridade naval, o ministro da cultura e o PAS.
Santa Catarina; 2) os primeiros resultados da análise do registro arqueológico e da pesquisa histórica sobre o naufrágio e a identificação da embarcação. Esta pesquisa, ao analisar o registro arqueológico e os dados históricos, possui três objetivos gerais: 1) estudar o barco e suas rotas;

${ }^{(* *)}$ Arqueólogo e Historiador, mergulhador. Professor aposentado da Universidade Estadual de Maringá. <ffnoelli@wnet.com.br> $\left.{ }^{(* *}\right)$ Bióloga, CRBio: 081326/03-D, formada pela Universidade Federal de Santa Catarina. <p.cardosomonteiro@gmail.com> $(* * *)$ Arquiteto, mergulhador, mestrando em Arqueologia Subaquática, Instituto Politécnico de Tomar.<dolito@ig.com.br> 
2) estudar a tripulação; 3) mapear os locais atacados pelos piratas. Seguimos o princípio da Nautical Archaeological Society, segundo o qual a "pesquisa histórica é uma exigência da arqueologia marítima, não uma opção extra” (NAS 2009: 65).

Apresentaremos aqui os dados que confirmam a hipótese de 2009, de que o barco pesquisado era aquele que as fontes históricas ${ }^{1}$ indicavam ser o liderado por Thomas Frins e mais sete ingleses, acusados de pirataria pelos espanhóis do Vice-Reino do Peru (1687), e pela justiça portuguesa no Brasil (1688).

Os resultados disponíveis em 2009 eram parciais e permitiam apenas hipóteses sobre o barco e sua origem no Vice-Reino do Peru. Para tanto, havia o suporte dos seguintes achados arqueológicos: 1) artefatos da América Central (um metate e cerâmicas indígenas); 2) artefatos ingleses (p. ex.: uma tampa com a Rosa Tudor e uma Escala de Gunter); 3) artefatos espanhóis (p. ex.: o barco naufragado, as botijas); 4) uma concha inicialmente classificada como Choncholepas concholepas (Bruguière, J. G. 1789), com ocorrência no Chile e Peru (ver revisão abaixo, nota 3). Também havia duas fontes históricas testemunhais de envolvidos diretamente com o barco da Praia dos Ingleses: 1) o depoimento de Thomas Frins, colhido pela justiça portuguesa na cidade de Santos (fevereiro de 1688), cujo resumo foi apresentado, em meados do século XVIII, pelo historiador Pedro Taques; 2) o diário de um dos cronistas da força pirata, Raveneau de Lussan, publicado como livro em 1690. Esses dados ligavam Frins à força pirata multinacional que assolou diversas localidades dos Vice-Reinos do Peru e da Nova Espanha, entre 1684 e 1687 (Noelli, Viana, Moura 2009). Todavia, a pesquisa histórica era incompleta devido à dificuldade de acesso às fontes primárias e a historiografia

(1) A pesquisa histórica foi realizada por Francisco S. Noelli. O historiador Amílcar de Mello D'Ávila indicou a informação crucial sobre a prisão dos ingleses na Ilha de Santa Catarina em 1687, ponto de partida para desvendar a origem do barco naufragado, objeto do projeto e das informações reveladas por este artigo. do Vice-Reino do Peru. Porém, conseguimos o suficiente para contextualizar e confirmar os ataques terrestres, os saques às colônias espanholas e a identidade do barco.

\section{Dados para determinar as escalas do naufrágio Praia dos Ingleses 1}

A definição das últimas rotas de navegação e escalas do barco é um dos objetivos deste artigo. Quando não existe o diário de bordo ou o relato de testemunhas, o reconhecimento depende do que se encontra no sítio arqueológico. Identificar o lugar de origem dos conteúdos do registro arqueológico é uma possibilidade para definir as rotas de viagem do barco e um ponto de partida para procurar fontes históricas. Entre os principais achados do sítio Praia dos Ingleses 1, selecionamos inicialmente: 1) madeiras do casco e do leme; 2) lastros de seixos e peças de alvenaria; 3) conchas de moluscos; 4) amostras de breu. Outros artefatos poderiam ser incluídos, mas entendemos que sua procedência poderia resultar de viagens marítimas de outros barcos, entrando a bordo por troca, comércio, saque etc. Contudo, para definir a história do barco, desde o lugar da construção, das suas viagens, até a posição onde terminou seus dias, depende de que "qualquer 'fato' presumido identificado durante a pesquisa no arquivo, precisa, quando possível, ser apoiado por evidência comprobatória de uma ampla variedade de fontes" (NAS 2009:65). Dos seis elementos selecionados acima, apresentamos aqui o resultado da análise das conchas ${ }^{2}$ que estavam na área do lastro. Devido à precisão dos limites geográficos onde ocorrem, as conchas informam sobre onde o barco navegou antes de naufragar na Praia dos Ingleses.

(2) Concha: um dos órgãos que constituem os moluscos, formado de carbonato de cálcio. Por ser um material rígido e resistente, dura por tempo indeterminado após a decomposição da parte mole do animal. A morfologia da concha e a forma de inserção do músculo do animal na concha são as características analisadas para sua classificação sistemática. 
A identificação e a classificação dos moluscos

O sítio Praia dos Ingleses 1 apresentou conchas de moluscos que não são da região da Ilha de Santa Catarina, nem do Oceano Atlântico. Foram identificadas cinco espécies: Anadara grandis (Broderip \& Sowerby 1829), Polymesoda (Neocyrena) sp. (Broderip 1833), Clypeolum latissimum (Broderip 1833); Strombus granulatus (Swainson 1822) e Tegula euryomphala (Jones 1844). Para a identificação e determinação da área de ocorrência, seguimos: 1) A. grandis = Abbott (1974); Abbott e Dance (1990); 2) P. (Neocyrena) sp. = Keen (2006), Severyn et al. (1994); 3) S. granulatus
= Abbott (1974; Abbott e Dance (1990); 4) C. latissimum = Abbott (1990), Eichhorst (2010); 5) T. euryomphala = Guzmán et al. (1998), Veliz \& Vasquez (2000); bases de dados biológicos on-line (FLMNH, 2010; GBIF, 2010; IABIN, 2010).

As conchas ocorrem apenas no Oceano Pacífico, entre o Golfo da Califórnia e o Chile (Fig. 1). É importante destacar que o Paralelo $5^{\circ} \mathrm{S}$ é um limite geográfico para a ocorrência das espécies (dependendo do período, mais ou menos quente \frio, o limite varia). Nas águas mais quentes acima do Paralelo habitam Anadara, Clypeolum Strombus e Polymesoda; abaixo do Paralelo, nas águas mais frias, ocorre a Tegula euryomphala.

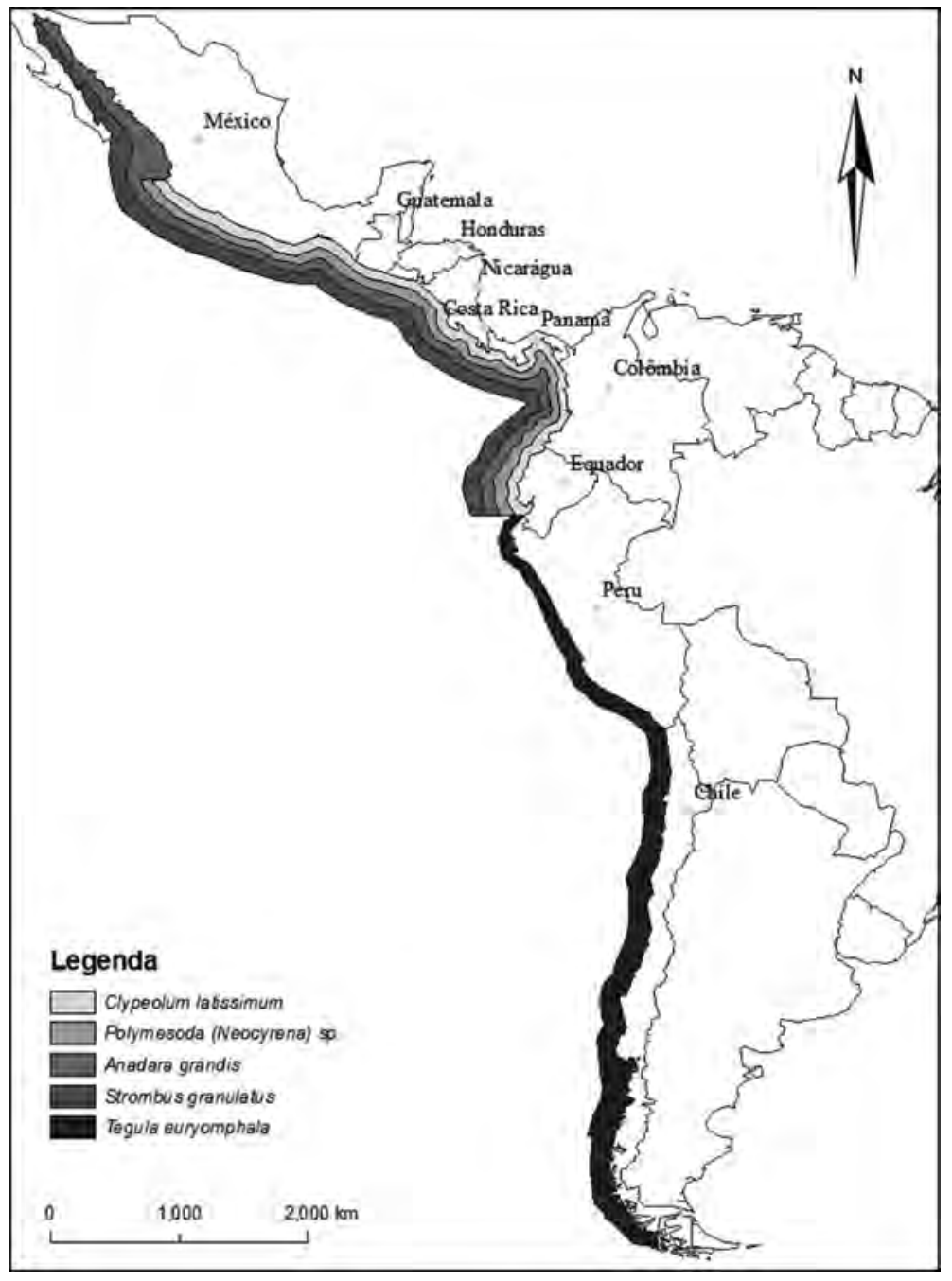

Fig. 1. Área de ocorrência das conchas. 
Anadara grandis (Broderip \& Sowerby 1829)

Classe BIVALVIA Linnaeus, 1758

Ordem Arcoida Stoliczka, 1871

Família Arcidae Lamarck, 1809

Subfamília Anadarinae Reinhart, 1935

Gênero Anadara Gray, 1847

O indivíduo adulto possui aproximadamente de 10 a $12 \mathrm{~cm}$ e pode alcançar 450 gramas de peso. Concha espessa e pesada, elevada, com 26 ou 27 costelas. Contorno quadrangular em seção; concha muito nodulosa, com área cardinal plana. Nos maiores fragmentos encontrados na Praia dos Ingleses, observou-se a presença de dentes taxodontes, área cardinal plana (Fig. 2), costelas robustas, grande espessura da valva, linha paleal e impressões musculares fortemente demarcadas, umbo e formato da concha, característicos de Anadara grandis.

A área de ocorrência vai da Baía de Madalena, México, até a Baía de Tumbes, no Peru, em 3030'S (Olsson 1961; Miranda-Baeza et al. 2006). Popularmente é conhecida como "pata de burro", devido ao seu formato. Em alguns ambientes, como os manguezais de Estero Real, na Nicarágua, e de Térraba-Sierpe, na Costa Rica, foram coletados até cinco milhões de indivíduos $\backslash$ ano para alimento, na década de 1980 (CATIE-IUCN 1990: 5). Os espécimes também serviam como artefatos. Foram encontrados em sítios arqueológicos litorâneos do México (Cabredo 1999; Voohies et al. 2002), Guatemala (Coe, Flannery 1967), Panamá (McGimsey 1956; Sapir 1968; Cooke 2001), Equador (Sarma 1974; Masucci 1995; Stahl 2003) e Peru (Lacerda (Ed.) 2001). No litoral norte do Peru, era explorado há mais de nove mil anos (Richardson 1998).

(3) Uma revisão \correção faz-se necessária em relação ao nosso primeiro artigo (Noelli, Viana, Moura 2009:185-

186): identificamos Anadara grandis erroneamente como Concholepas concholepas.
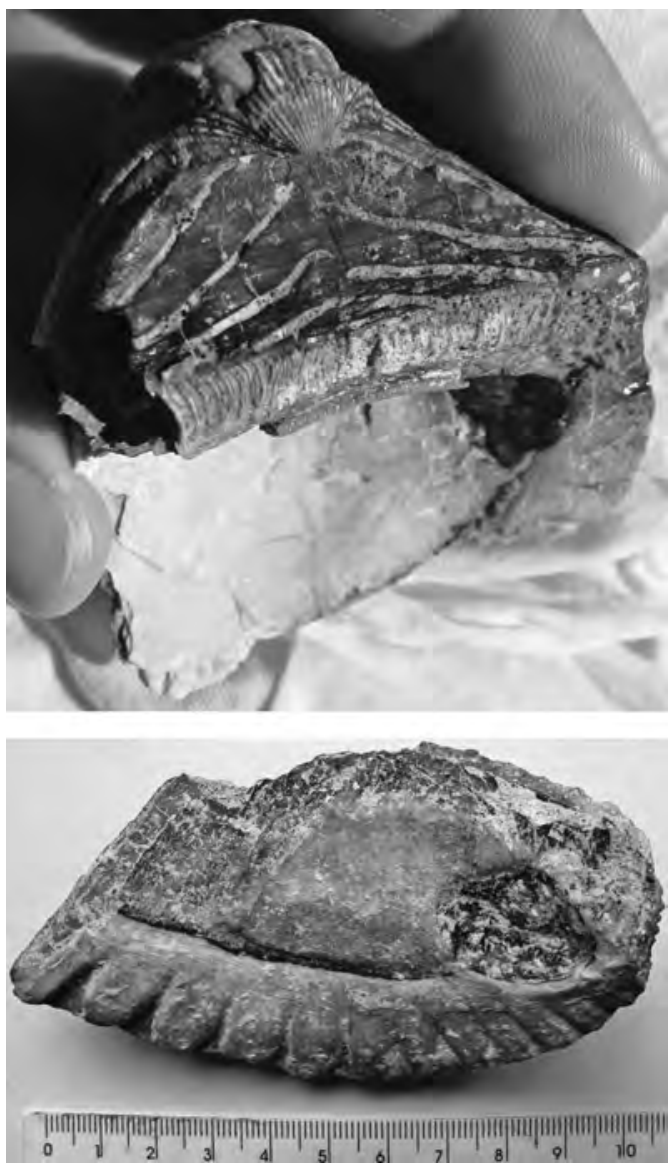

Fig. 2. Fragmentos de Anadara grandis.

\section{Polymesoda (Neocyrena) sp. (Broderip, 1833)}

Classe BIVALVIA Linnaeus, 1758

Ordem Veneroida H. \& A. Adams, 1856

Família Corbiculidae Gray, 1847

Gênero Polymesoda Rafinesque, 1820

Subgênero Neocyrena Crosse \& Fischer, 1894

O periostraco é, geralmente, escuro ou verde oliva, com bandas pretas radiadas que vão do umbo até a margem ventral da concha. O seio paleal é bem desenvolvido, com a inserção do músculo variável em tamanho e posição; sempre em um "V" aberto. Parte interna da concha é geralmente violeta, tanto em manchas como totalmente colorida; em algumas espécies podem ser brancas ou rosas e apresentam o periostraco amarelo. As violetas podem ter tons rosa ou 
pêssego. A partir dos espécimes que apresentavam a charneira e margem ventral conservadas, pôde-se perceber a presença dos três dentes cardinais em cada charneira e os laterais anteriores e posteriores, além de seio paleal em "V". O padrão radiado da concha se manteve, apesar de a coloração poder ter sido alterada pelo desgaste do periostraco (Fig. 3). Este subgênero é amplamente distribuído ao longo da América Central e norte da América do Sul, nos Oceanos Pacífico e Atlântico (Severeyn, Severeyn, Ewald 1994). Para Keen (2006: 114), ainda existem problemas para classificar as Polymesodas, uma vez que "coleções cuidadosas nos estuários da costa da
América Central são necessárias antes que uma lista realmente satisfatória possa ser publicada”.

Como a amostra foi encontrada com espécies exclusivas do Pacífico, usadas como cal em peças de alvenaria, eliminou-se a possibilidade de a ocorrência ser do Atlântico. As pesquisas arqueológicas mostraram que o gênero Polymesoda era apreciado no litoral do México para a elaboração de artefatos (Cabredo 1999) e piso (Voohies et al. 2002). Foram encontradas como restos alimentares em sítios costeiros da Guatemala (Coe, Flannery 1967), Panamá (Sapir 1968) e Equador (Sarma 1974; Stahl 2003).


Fig. 3. Polymesoda (Neocyrena) sp. 


\section{Clypeolum latissimum (Broderip, 1833)}

Classe GASTROPODA Cuvier, 1797

Ordem Archaeogastropoda Thiele, 1925

Família Neritidae Rafinesque, 1815

Gênero Clypeolum Récluz, 1842

A concha é hemiglobosa, moderadamente fina e leve, com a última volta visivelmente alada nos indivíduos adultos. Não há cordas espirais, apenas leves linhas de crescimento. Região parietal achatada; lábio interno plano com numerosos pequenos dentículos. Opérculo cinza escuro ou preto. Malha reticulada triangular (Fig. 4). Indivíduos adultos apresentam de 2 a $3,8 \mathrm{~cm}$. Habita a desembocadura de pequenos rios. Sua área de ocorrência vai desde o sudeste do México até Guayaquil no Equador. Foi explorada como alimento em sítios arqueológicos do Equador (Stahl 2003).

\section{Strombus granulatus (Swainson, 1822)}

Classe GASTROPODA Cuvier, 1797

Ordem Caenogastropoda Cox, 1960

Família Strombidae Rafinesque, 1815

Gênero Strombus Linné, 1758

O indivíduo possui em média, de 5 a 9 $\mathrm{cm}$. Espira pequena e tuberculada; voltas com

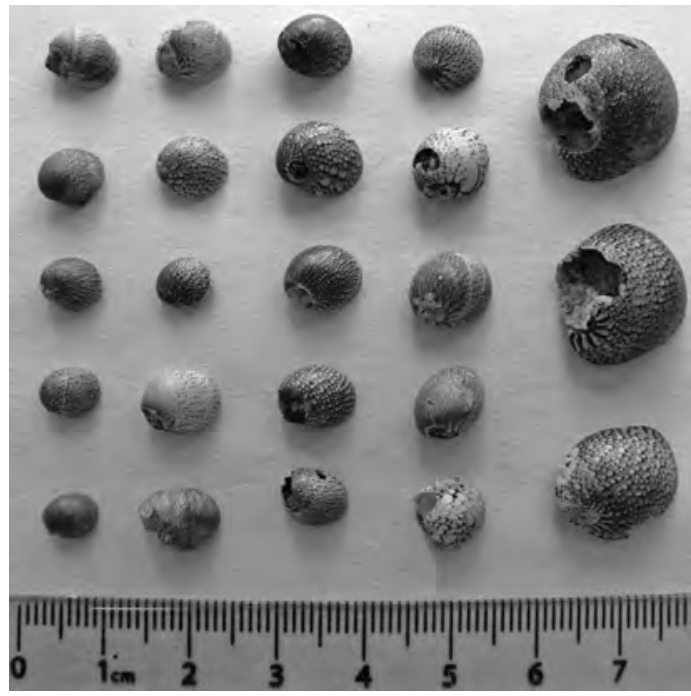

Fig. 4. Clypeolum latissimum. cinco cordas espirais, com a mais apical apresentando uma ponta saliente. Na parte interna do lábio externo, há numerosas granulações. Comum em águas rasas e até 75 metros de profundidade. $O$ espécime foi encontrado com desgastes, mas permaneceu o padrão espiralado e nodulado da concha, assim como o padrão alongado e largo do lábio externo e suas granulações, sendo características decisivas para a sua identificação (Fig. 5). A espécie ocorre desde o Golfo da Califórnia, no México, até o Equador, inclusive em Galápagos (Schwengel 1938).

O uso mais comum de Strombus granulatus é como artefato, eventualmente como alimento. Paulsen (1974) e Masucci (1995), após extensa revisão, mostram que foi um artefato com grande significado e altamente valorizado, comumente encontrado fora de suas áreas de ocorrência devido a uma ampla rede de comunicação. Encontrado em escavações arqueológicas no litoral do México (Cabrero 1999), Guatemala (Coe, Flannery 1967), Panamá (Sapir 1968; Cooke 2001), litoral e interior do Equador (Meggers, Evans, Estrada 1965; Paulsen 1974; Sarma 1974; Masucci 1995; Stahl 2003; Valdez 2008), e no litoral norte e interior do Peru (Paulsen 1974; Burger 2008; Moore, Mackey 2008).

\section{Tegula euryomphala (Linnaeus 1758)}

Classe GASTROPODA Cuvier, 1797

Ordem Archaeogastropoda Thiele, 1925

Família Trochidae Rafinesque, 1815

Subfamília Monodontinae Cossmann, 1916

Gênero Tegula Lesson, 1835
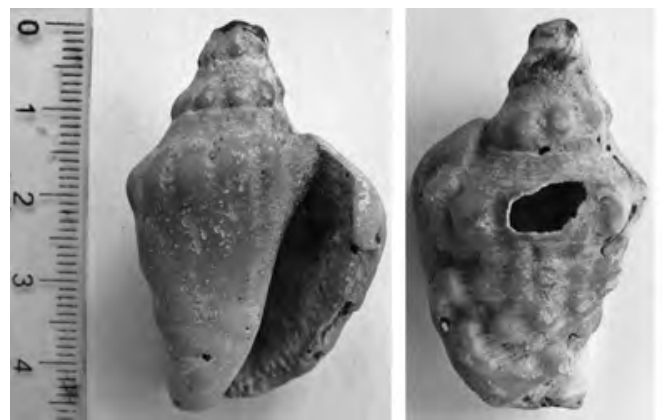

Fig. 5. Strombus granulatus. 
Concha com espiras relativamente elevadas, arredondadas e lisas, com quatro voltas. Apresenta um dente columelar e umbílico grande e profundo. Lábio externo fino e cortante. Apresenta um dente próximo à base que se prolonga em uma costela até o umbílico. A coloração externa é púrpura escura; alcança tamanhos de até 2,8 cm (Fig. 6). Distribui-se em áreas protegidas de ondas, com menor movimentação de água. $O$ limite norte da espécie fica pelos $5^{\circ} \mathrm{S}$, no Peru, na chamada Zona de Transição de Paita, devido aos efeitos da Corrente de Humboldt na temperatura da água (Guzmán et al. 1998; Moore 1991). O limite sul ainda é discutido, estando entre os $36^{\circ} \mathrm{S}$ (Tacalhuano) e $30^{\circ} 41^{\prime} \mathrm{S}$ (Coquimbo) (Veliz, Vásquez 2000). Apesar de o gênero Tegula, principalmente a espécie atra, ser comum nos sítios arqueológicos chilenos, T. euroymphala é raramente encontrada em antigos assentamentos humanos. Em outras regiões, como na Califórnia, Tegula spp., que é pequena e difícil de processar (baixo rendimento de carne), aumenta no registro arqueológico quando

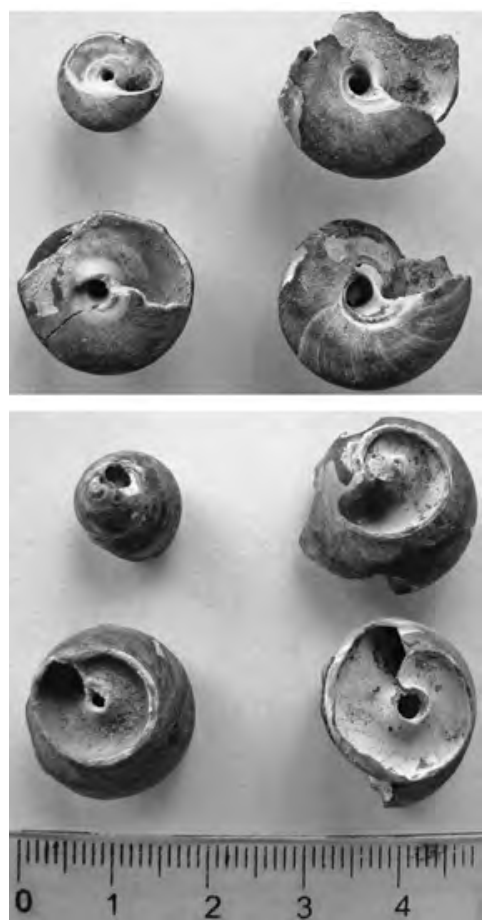

Fig. 6. Tegula euryomphala. espécies maiores, como Anadara grandis (fácil de processar, com alto rendimento de carne) eram exauridas pela exploração (Raab 1992 apud Mannino e Thomas 2002).

\section{As conchas no contexto arqueológico}

Foram encontradas e analisadas 114 unidades de conchas inteiras e fragmentadas. Do total, apenas 20 saíram diretamente do contexto arqueológico em 2009. As outras 94 foram coletadas em terra, entre as 29 toneladas de lastro removidas da área de escavação e acondicionadas na base de pesquisa da Praia dos Ingleses. A Tabela 1 apresenta a quantidade de espécimes, dividida em unidades inteiras e fragmentadas:

A. grandis compõe a maioria da amostra, com 49\%; seguida por C. latissimum (34\%), P. (Neocyrena) sp. (12\%), T. euryomphala (4\%) e S. granulatus (1\%) (Fig. 7). Cabe destacar que se encontrou grande quantidade de pequenos fragmentos semelhantes à composição e coloração de A. grandis, que não foram analisados por não apresentar características determinantes para identificar a espécie. S. granulatus e T. euryomphala foram encontrados somente na área da escavação, não ocorrendo nas coletas realizadas em terra em 2010.

A amostra analisada foi extraída da superfície de 100 peças de lastro de alvenaria, cada unidade com área média de $0,152 \mathrm{~m}^{2}$ (d.p.= 0,09), somando $15,22 \mathrm{~m}^{2}$. Das 100 peças, $42 \%$ não apresentaram espécime macroscópico identificável e, em $58 \%$, foram encontrados de um a três espécimes (exemplos na Fig. 8). Como o lastro de alvenaria estava fragmentado pelo processo pós-deposicional de formação do registro arqueológico, as unidades examinadas apresentaram conchas isoladas ou agrupadas de duas a três espécies.

O lastro de alvenaria foi preparado e embarcado em um local específico. O cimento é composto por areia, pequenos seixos e conchas moídas grosseiramente usadas como cal. Foi moldado sobre a quilha, situado a meia nau, do centro para a ré do barco, concentrado em uma única área. Estava diretamente 
Tabela 1

Quantidade de espécimes encontrados

\begin{tabular}{|c|c|c|c|c|c|}
\hline \multicolumn{6}{|c|}{ Quantidade de espécimes encontrados } \\
\hline \multirow{2}{*}{ Classe/ Espécie } & \multicolumn{2}{|c|}{ Espécimes coletados 2009} & \multicolumn{2}{|c|}{ Espécimes coletados 2010} & \multirow{2}{*}{ TOTAL } \\
\hline & Inteiro & Fragmento & Inteiro & Fragmento & \\
\hline \multicolumn{6}{|l|}{ Bivalvia } \\
\hline Anadara grandis & 0 & 6 & 0 & 50 & 56 \\
\hline Polymesoda boliviana & 2 & 2 & 6 & 4 & 14 \\
\hline \multicolumn{6}{|l|}{ Gastropoda } \\
\hline Clypeolum latissimum & 5 & 0 & 33 & 1 & 39 \\
\hline *Strombus granulatus & 1 & 0 & 0 & 0 & 1 \\
\hline${ }^{*}$ Tegula atra auryomphala & 1 & 3 & 0 & 0 & 4 \\
\hline ТОТАI & 9 & 11 & 36 & 54 & 114 \\
\hline & \multicolumn{2}{|c|}{20} & \multicolumn{2}{|c|}{94} & \\
\hline
\end{tabular}

\section{Porcentagem de espécimes encontrados}

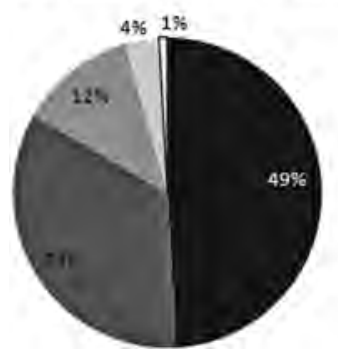

- Anadaragrandis

- Clypeolum latissimum

- Polymesodaboliviana

Tegula euryomphala

․ Strombus gramulatus

Fig. 7. Porcentagem de espécimes encontrados.

sobre as pranchas do fundo e, no contexto arqueológico, marcava alguns negativos de cavernas, que se deterioraram completamente na formação do contexto arqueológico. Provavelmente serviu para acrescentar peso provisoriamente, em um local que não oferecia material rochoso considerável para garantir a estabilidade da embarcação, pois a permanência dessa configuração causaria o apodrecimento das pranchas do casco e de peças estruturantes. Não é comum o emprego de reforços de alvenaria na construção de barcos de madeira e não encontramos exemplos na bibliografia de arquitetura náutica e de história marítima. O lastro de seixos e blocos rochosos era móvel para ser retirado ou transferido conforme a necessidade, durante a navegação ou nas carenagens em terra (as manutenções periódicas de calafetagem, substituição de pranchas ou outras partes do casco, raspagem das cracas e remoção de teredos na parte externa do casco abaixo da linha d'água, assim como para limpeza do porão, para remover limo, material orgânico, lixo e decomposições devidas ao ambiente molhado e úmido - a água acumulada no porão era constantemente drenada por bombas manuais).

O mais importante é destacar que essa alvenaria marca uma escala do barco, onde foram coletados os moluscos para fazer o cimento. Observando na Fig. 1 a distribuição geográfica dos espécimes, verifica-se que o lugar está situado entre o México e o Equador, devido aos limites de C. latissimum, A. grandis e P. (Neocyrena sp.). O lugar específico poderá ser determinado com a análise da composição isotópica do estrôncio, do carbono e do oxigênio das conchas do naufrágio. Também poderíamos acrescentar outros marcadores, como a assinatura geoquímica das rochas do lastro e do sedimento do cimento, para compará-las com as amostras de conchas. Os exemplares de T. euryomphala ocorrem mais ao sul em relação às demais espécies. Eles estavam 



Fig. 8. Ocorrência de espécimes isolados ou agrupados em um mesmo pedaço de lastro de alvenaria. A: C. latissimum e P. boliviana; B: A. grandis e P. boliviana; C: C. latissimum e A. grandis; D: C. latissimum; E: A. grandis; F: P. boliviana.

fixados apenas nos seixos de basalto vesicular do lastro da embarcação, não ocorrendo nas peças de alvenaria. Estes seixos compõem mais de $60 \%$ das 29 toneladas de lastro retiradas do sítio arqueológico. Tal proporção sugere que o basalto foi o lastro original, inserido no estaleiro onde o barco foi construído. O limite norte da ocorrência da T. euryomphala, próximo do paralelo $5^{\circ} \mathrm{S}$, também sugere que os seixos foram coletados em algum local próximo da baía de Guayaquil, cuja região possui inúmeras fontes de basalto vesicular.
O exemplar do jovem S. granulatus não parece estar associado ao lastro. É provável que fosse de uso pessoal com significado simbólico, como referimos acima. Também pode indicar algo sobre a tripulação, que poderia ter componentes indígenas, apesar de as fontes históricas não informarem especificamente. Da mesma forma, o metate e as cerâmicas arqueológicas também podem ser indicativos da presença de indígenas a bordo. Em último caso, tais objetos estariam a bordo pelas mãos europeias, para processar milho (metate), servir alimentos e bebidas (vasilhas cerâmicas) e adorno pessoal. 
Comparação entre a área de ocorrência das conchas e os roteiros da força pirata no Oceano Pacífico

Os diários de bordo dos piratas e os relatos das testemunhas espanholas colocam os barcos piratas na mesma área de ocorrência das cinco espécies de conchas encontradas no registro arqueológico do sítio Praia dos Ingleses 1 (Tabelas 2, 3 e 4). Para estabelecer a relação entre os barcos, o espaço navegado e as áreas de ocorrência das conchas, precisamos considerar que os piratas não atuaram sempre como um grupo unificado e que, separados, atacavam simultaneamente locais espalhados por uma vasta área (Burney 1816; Lohmann Villena 1975; Bradley 1999; Gerhard 2003). Dependendo da circunstância, a frota reunia-se para um ataque conjunto ou, como foi mais comum, espalhava-se para atacar alvos diferentes em um mesmo mês. Em geral, os grupos menores eram compostos por dois ou três barcos, um deles com artilharia. E, muitas vezes, vários barcos também agiram isoladamente. Além disso, salvo os três barcos que vieram da Europa (o Bachelor's Delight, o Nicholas e o Cygnet), todas as demais embarcações usadas pelos piratas foram capturadas pelos espanhóis, sendo barcos construídos e mantidos com materiais encontrados naquela parte do Oceano Pacífico.

Os cronistas piratas e os espanhóis descreveram o cotidiano dos barcos e das suas tripulações na área entre o Chile e o sul da Califórnia, de 1684 a 1687. A descrição mais completa sobre os piratas ingleses foi publicada por William Dampier em 1699, no primeiro volume do livro A New Voyage round the World. Describing particularly the Isthmus of America, several coasts and islands in the West Indies... A Tabela 2 mostra as escalas registradas por Dampier, entre $1683 \mathrm{e}$ janeiro de 1686.

O relato de Dampier foi interrompido em janeiro de 1686, quando seu barco zarpou para as Filipinas. A descrição da continuidade das ações inglesas, entre 1686-1687, foi feita em parte por Lionel Wafer, cirurgião que passou a maior parte da expedição com Edward Davis, no Bachelor's Delight. Wafer publicou, em 1699, o livro A New Voyage and description of the
Isthmus of America..., que ficou mais conhecido por sua importância como diário de naturalista. Wafer também contribui para corroborar o testemunho das demais fontes contemporâneas das ações dos piratas, que citaremos na Tabela 4 .

O relato mais completo sobre os franceses da força pirata é de Raveneau de Lussan. Seu Journal du voyage fait à la mer $d u$ Sud, avec les flibustiers de l'Amérique en 1684 et années suivantes, apresenta uma lista de locais onde os barcos franceses aportaram entre 1685 e 1687 (Tabela 3).

Consideramos na Tabela 3 apenas as escalas $\backslash$ ataques franceses realizados até 12 de abril de 1687, data do encontro com o barco desgarrado da força de E. Davis, tripulado por oito ingleses, sobre o qual trataremos abaixo. As fontes espanholas confirmam os relatos dos piratas sobre os locais atacados e de outras ações observadas no litoral dos Vice-Reinos do Peru e da Nova Espanha. Seus testemunhos, junto com o livro de Wafer (1704), estão apontados na Tabela 4, que consideramos incompleta por não estar concluído o levantamento das fontes espanholas.

Os lugares indicados nas Tabelas 2, 3 e 4, podem ser observados nas Figs. 9 e 10.

\section{$\mathrm{O}$ barco dos oito ingleses}

No artigo anterior (Noelli, Viana e Moura 2009) começamos a definir a identidade do barco naufragado na Praia dos Ingleses apenas com dados do registro arqueológico e duas fontes escritas independentemente. Também possuíamos o livro de Lionel Wafer e o relato do vice-rei do Peru, Melchor de Navarra y Rocaful ([1689] 1859), mas não os usamos porque eram vagos e incompletos sem o apoio de outras fontes. Posteriormente, em 2012, localizamos o testemunho chave para desvendar a identidade do barco dos oito ingleses, escrito em 1688, por um padre jesuita que atuava na região. $\mathrm{O}$ importante é que os testemunhos independentes contêm, apesar de pequenas discrepâncias, partes da mesma estrutura narrativa sobre um barco capturado pelos espanhóis, navegando solitário e com apenas oito ou sete ingleses, desgarrado do grupo de Edward Davis em 1686 e que pretendia retornar ao Oceano Attântico. 
Tabela 2

\begin{tabular}{|c|c|c|}
\hline \multicolumn{3}{|c|}{ Escala dos barcos ingleses, 1683-1685, cf. W. Dampier } \\
\hline \multicolumn{3}{|c|}{ Barcos } \\
\hline Bachelor's Delight & Nicholas & Cygnet \\
\hline Partida: Serra Leoa* $11 / 1683$ & Partida: Londres 11/06/1683 & Partida: Londres $1 / 10 / 1683$ \\
\hline Local $\backslash$ dia $\backslash$ mês $\backslash$ ano & Local $\backslash$ dia $\backslash$ mês $\backslash$ ano & Local $\backslash$ dia $\backslash$ mês $\backslash$ ano \\
\hline I. Malvinas - 28/1/1684 & I. Madeira & Porto Hambre \\
\hline Estreito de La Maire - 6/2/84 & I. Cabo Verde & Valdívia - 3/1684 \\
\hline I. Juan Fernández - 22/3/84 & Costa SE brasileira & I. Mocha diego barros Arana 2000: v. 5 \\
\hline I. Lobos $-9 / 5 / 84$ & Rio de la Plata & hist gen chile \\
\hline Baía Tortugas* ${ }^{*}$ 10/5/84 & Porto Hambre & Nicoya $-8 ? / 84$ \\
\hline I. Galápagos - 1/6/84 & I. Juan Fernández - 22/3/84 & I. Plata* $-2 / 10 / 1684$ \\
\hline C. Blanco $-2 / 7 / 84$ & I. Lobos - 9/5/84 & Paita - 2/11/84 \\
\hline Baía de la Caldera - 2/7/84 & Baía Tortugas* - 10/5/84 & Colán y Piura - 3/11/84 \\
\hline Nicoya $-2 / 7 / 84$ & I. Galápagos - 1/6/84 & I. Lobos* ${ }^{*}$ 14/11/84 \\
\hline Realejo $-23 / 7 / 84$ & C. Blanco $-2 / 7 / 84$ & I. Puna - 12/84 \\
\hline Amapalla (I. Tigre)* - 27/7/84 & Baía de la Caldera - 2/7/84 & Guayaquil - 9/12/84 \\
\hline C. San Francisco - 20/9/84 & Nicoya $-2 / 7 / 84$ & I. Plata $-16 / 12 / 84$ \\
\hline I. Plata - 20/9/84 & Realejo $-23 / 7 / 84$ & C. Passao - 24/12/84 \\
\hline I. Santa Helena** - 9/84 & Amapalla (I. Tigre)* - 27/7/84 & Rio Santiago (Tomaco) - 27/12/84 \\
\hline Manta - 9/84 & I. $\operatorname{Cocos}-8 / 84$ & I. Gallo* $-1 / 1 / 84$ \\
\hline I. Plata* $-26 / 9 / 84$ & I. Galápagos & I. Gorgonia - 9/1/85 \\
\hline Paita - 2/11/84 & C. San Francisco - 9/84 & I. del Rey* $-25 / 1 / 85$ \\
\hline Colán y Piura - 3/11/84 & I. Plata $-22 / 9 / 84$ & Pacheque - 16/2/85 \\
\hline I. Lobos* $-14 / 11 / 84$ & Paita - 10/84 & I. Perico - 20/2/85 \\
\hline I. Puna - 12/84 & I. Lobos - 11/84 & I. Tabago $-24 / 2 / 85$ \\
\hline Guayaquil - 9/12/84 & & Golfo de San Miguel (Dárien) - 3/3/85 \\
\hline I. Plata - 16/12/84 & & I. del Rey $-2 / 3 / 85$ \\
\hline C. Passao - 24/12/84 & & I. Pacheque - 1/4/85 \\
\hline Rio Santiago (Tomaco) - 27/12/84 & & I. Tabago - 3/4/85 \\
\hline I. Gallo* $-1 / 1 / 85$ & & I. Chepelio - 22/4/85 \\
\hline I. Gorgonia - 9/1/85 & & I. Tabago $-28 / 4 / 85$ \\
\hline I. del Rey ${ }^{*}-25 / 1 / 85$ & & I. del Rey $-4 / 5 / 85$ \\
\hline I. Pacheque - 16/2/85 & & I. Chepelio - 27/5/85 \\
\hline I. Perico - 20/2/85 & & I. Coiba - 15/6/85 \\
\hline I. Tabago - 24/2/85 & & Realejo - 9/8/85 \\
\hline I. del Rey - 2/3/85 & & $14^{\circ} 30^{\prime} \mathrm{N}$ (costa da Guatemala) -24/9/85 \\
\hline I. Pacheque - $1 / 4 / 85$ & & I. Tangola $-2 ? / 10 / 85$ \\
\hline I. Tabago $-3 / 4 / 85$ & & Guatulco - 4?/10/85 \\
\hline I. Chepelio - 22/4/85 & & I. Sacrifício - 12/10/85 \\
\hline I. Tabago - 28/4/85 & & Puerto Angel - 27/10/85 \\
\hline I. del Rey - 4/5/85 & & Acapulco - 7/11/85 \\
\hline I. Pacheque $-22 / 5 / 85$ & & Chequetan - 18/11/85 \\
\hline I. Coiba - 15/6/85 & & Telupan (Colima) - 26/11/85 \\
\hline Realejo - 9/8/85 & & Salagua - 1/12/85 \\
\hline León - c. 20/8/85 & & C. Corrientes - 11/12/85 \\
\hline Realejo - 27/8/85 (Davis, Harris, & & I. Chametly - 20/12/85 \\
\hline Knight, partiram rumo ao sul) & & C. Valderas - 1/1/86 \\
\hline
\end{tabular}

${ }^{*}=$ local de carenagem; ${ }^{* *}=$ local de coleta de betume; I.= ilha; C. = cabo; $\mathrm{c}$. = circa 
Tabela 3

\begin{tabular}{|c|c|c|}
\hline \multicolumn{3}{|c|}{ Escala dos barcos franceses, $1685-1687$, cf. R. de Lussan } \\
\hline 1685 & 1686 & 1687 \\
\hline Local $\backslash$ dia $\backslash$ mês $\backslash$ ano & Local $\backslash$ dia $\backslash$ mês $\backslash$ ano & Local $\backslash$ dia $\backslash$ mês $\backslash$ ano \\
\hline B. de la Boca Chica - $12 \backslash 4$ & I. Coiba - $1 \backslash 1$ & Nicoya $\backslash$ Sta Catalina* $-1 \backslash 1$ \\
\hline I. del Rey - $18 \backslash 4$ & Chiriquita - $6 \backslash 1$ & I. La Cagna - $2 \backslash 1$ \\
\hline R. Chepo - 28\4 & I. Coiba - $16 \backslash 1$ & Nicoya $-13 \backslash 1$ \\
\hline I. Chepelio - $1 \backslash 5$ & I. San Pedro - 14\3 & Esparso $\backslash$ Nicoya - $22 \backslash 1$ \\
\hline I. Taboga* $-8 \backslash 5$ & Chiriquita - 14\3 & Nicoya - $12 \backslash 2$ \\
\hline I. del Rey - $19 \backslash 5$ & I. Coiba - 14\3 & P. Sta. Helena - $12 \backslash 4$ \\
\hline C. Pin - 29 \5 & Boca Toro - $9 \backslash 4$ & (local do encontro com o barco dos oito ingleses) \\
\hline R. Chepo - $1 \backslash 6$ & Esparso $\backslash$ Nicoya - 19\4 & \\
\hline I. Chepelio - $4 \backslash 6$ & C. Blanco - $7 \backslash 5$ & \\
\hline Cidade do Panamá - $8 \backslash 6$ & Granada $-7 \backslash 5$ & \\
\hline I. Coiba $-14 \backslash 6$ & Massaya $-7 \backslash 5$ & \\
\hline Pueblo Nuevo - $31 \backslash 6$ & Chinandega $-2 \backslash 5$ & \\
\hline Santiago de Veragua - $9 \backslash 8$ & Realejo $-28 \backslash 5$ & \\
\hline Iguana Cliff - $15 \backslash 8$ & B. Culebra - $23 \backslash 5$ & \\
\hline I. Coiba - $3 \backslash$ set & C. Boca Toro - $1 \backslash 6$ & \\
\hline G. Nicoya (B. Caldera) - 19\9 & I. Montosa $-7 \backslash 6$ & \\
\hline B. Culebra - $20 \backslash 10$ & I. Coiba - $10 \backslash 6$ & \\
\hline G. Papagayo - $20 \backslash 10$ & Villia $-13 \backslash 6$ & \\
\hline Realejo* $-22 \backslash 10$ & Punta Mala - $19 \backslash 6$ & \\
\hline León - $8 \backslash 11$ & Porto $s \backslash$ nome $-21 \backslash 6$ & \\
\hline Pueblo Viejo* - 14\11 & Puercos - 9\7 & \\
\hline B. Culebra - $3 \backslash 12$ & I. Galera - $13 \backslash 7$ & \\
\hline Esparsa - 9\12 & C. Pin $-18 \backslash 7$ & \\
\hline P. Burica - $14 \backslash 12$ & I. del Rey $-25 \backslash 7$ & \\
\hline Chiriquita - 22\12 & Cidade do Panamá - 30\7 & \\
\hline & R. Chepo - $1 \backslash 8$ & \\
\hline & I. Otoqua - $3 \backslash 8$ & \\
\hline & I. Taboga - $5 \backslash 8$ & \\
\hline & I. del Rey - $9 \backslash 8$ & \\
\hline & R. Boca Chica - $11 \backslash 8$ & \\
\hline & I. del Rey* $-9 \backslash 8$ & \\
\hline & I. Taboga - $21 \backslash 8$ & \\
\hline & I. Otoqua $-5 \backslash 10$ & \\
\hline & I. del Rey - 10 \10 & \\
\hline & Cidade do Panamá - 17\10 & \\
\hline & I. del Rey - 19\10 & \\
\hline & I. Otoque - $24 \backslash 10$ & \\
\hline & I. Iguana - $2 \backslash 11$ & \\
\hline & I. Coiba - 16\11 & \\
\hline & Pueblo Nuevo - $24 \backslash 11$ & \\
\hline & P. San Lorenzo - $26 \backslash 11$ & \\
\hline & Boca Toro (P. Burica) - $5 \backslash 12$ & \\
\hline
\end{tabular}

* = local de carenagem; ** = local de coleta de betume; I. = ilha; C. = cabo; c. = circa 
Tabela 4

\begin{tabular}{|c|c|}
\hline \multicolumn{2}{|c|}{ Escalas dos barcos ingleses, cf. as fontes espanholas e L. Wafer, 1686-1687 } \\
\hline Local $\backslash$ dia $\backslash$ mês $\backslash$ ano & Local $\backslash$ dia $\backslash$ mês $\backslash$ ano \\
\hline P. Tongoy - La Serena \10\1685 & Concha 1871:274 \\
\hline I. Cocos & Bradley 1999:482 \\
\hline I. Galápagos & Mackenna 264; Lane 1999:152; Bradley 1999:482 \\
\hline Huanchaco $\backslash 2 \backslash 1686$ & Lane 1999:152; Bradley 1999:483 \\
\hline Chérrepe $\backslash 3 \backslash 1686$ & López y Martínez 1688; Mugaburu 1935:250 \\
\hline Saña \3\1686 & López y Martínez 1688; Mugaburu 1935:250 \\
\hline I. de los Lobos $\backslash 3 \backslash 1686$ & López y Martínez 1688 \\
\hline Paita $\backslash 3 \backslash 1686$ & López y Martínez 1688; Mugaburu 1935:250 \\
\hline Colán \4\1686 & Mugaburu 1935:250 \\
\hline Huaura $\backslash 5-6 \backslash 1686$ & López y Martínez 1688; Mugaburu 1935:250-1; Lohmann Vilhena \\
\hline Huacho $\backslash 5 \backslash 1686$ & $1975: 494$ \\
\hline Huarmey $\backslash 5 \backslash 1686$ & López y Martínez 1688; Mugaburu 1935:250; Bradley 2009:198 \\
\hline Chancay $\backslash 5-6 \backslash 1686$ & Mugaburu 1935:252 \\
\hline P. Tongoy \Coquimbo \La Serena $\backslash 7 \backslash 1686$ & López y Martínez 1688; Lane 1999:152 \\
\hline Limarí $\backslash 7 \backslash 1686$ & Mugaburu 1935:253; Concha 1871:55-56; Arana 2000:177 \\
\hline Pisco $\backslash 7 \backslash 1686$ & Arana 2000:177 \\
\hline Nazca $\backslash 1686$ & Wafer 1704:156; López y Martínez 1688, Mugaburu 1935:253 \\
\hline Arica $\backslash 1686$ & Wafer $1704: 156$ \\
\hline Santa (María de la Parrilla) \1686 & López y Martínez 1688 \\
\hline Copiapó \1686 & Mugaburu 1935:250; Mackenna 264 \\
\hline Casma $\backslash 6 \backslash 1686$ & Arana 2000:177 \\
\hline Huarney $\backslash 7 \backslash 1686$ & Mugaburu 1935:250; Odriozola 1865:17; Lane 1999:152 \\
\hline Callao $\backslash 7 \backslash 1686$ & Mugaburu 1935:250; Mackenna 265; Bradley 1999:484, 2009:198; \\
\hline Saña $\backslash 7 \backslash 1686$ & Bradley 1999:484; Lane 1999:153 \\
\hline Trujillo $\backslash 8 \backslash 1686$ & Bradley 1999:484 \\
\hline Ica $\backslash 8 \backslash 1686$ & Bradley 1999:484 \\
\hline Caballas \8\1686 & Bradley 1999:484 \\
\hline Nazca $\backslash 9 \backslash 1686$ & Bradley 1999:484 \\
\hline Coquimbo \La Serena $\backslash 9 \backslash 1686$ & Wafer 1704:157; Bradley 1999:484 \\
\hline I. Juan Fernandez* $\backslash 9 \backslash 1686$ & Wafer 1704:157; Arana 2000:179; Bradley 1999:484 \\
\hline I. Mocha $\backslash 12 \backslash 1686$ & Wafer 1704:158; Mackenna 269 \\
\hline Huasco \12\1686 & Wafer 1704:158; Bradley 1999:484 \\
\hline Copiapó \12\1686 & Arana 2000: 181 \\
\hline Arica $\backslash 2 \backslash 1687$ & Wafer 1704:161; Mackenna 269 \\
\hline Ilo $\backslash 1687$ & Wafer 1704:163; Lohmann Vilhena 1975:437 \\
\hline Bermejo $\backslash 1687$ & Wafer 1704:163 \\
\hline Cañete $\backslash 2 \backslash 1687$ & Wafer 1704:166 \\
\hline "Wormia" (Huarmey) \4\1687 & Mugaburu 1935:263; Lohmann Vilhena 1975:437 \\
\hline  & Mugaburu 1935:267; Wafer 1704:167 \\
\hline Casma $\backslash 5 \backslash 1687$ & Mugaburu 1935:269-270 \\
\hline Trujillo $\backslash 5 \backslash 1687$ & Mugaburu 1935:270 \\
\hline Santa (María de la Parrilla) \5\1687 & López y Martínez 1688 \\
\hline Tumbes $\backslash 1687$ & Wafer 1704:168; López y Martínez 1688 \\
\hline I. la Plata $\backslash 1687$ & López y Martínez 1688 \\
\hline Pisco $\backslash 5 \backslash 1687$ & López y Martínez 1688 \\
\hline Paita $\backslash 5 \backslash 1687$ & Mackenna 271 \\
\hline Guayaquil $\backslash 5 \backslash 1687$ & Burney ; Mackenna 271 \\
\hline I. Galápagos \1687 & Mackenna 272; Bradley 1999:488 \\
\hline I Páscoa $\backslash 1687$ & Wafer 1704:169; Mackenna 273 \\
\hline I. Mocha $\backslash 11 \backslash 1687$ & Arana 2000:182 \\
\hline
\end{tabular}

* = escala de carenagem; I.= ilha; C. = cabo; P. = porto 


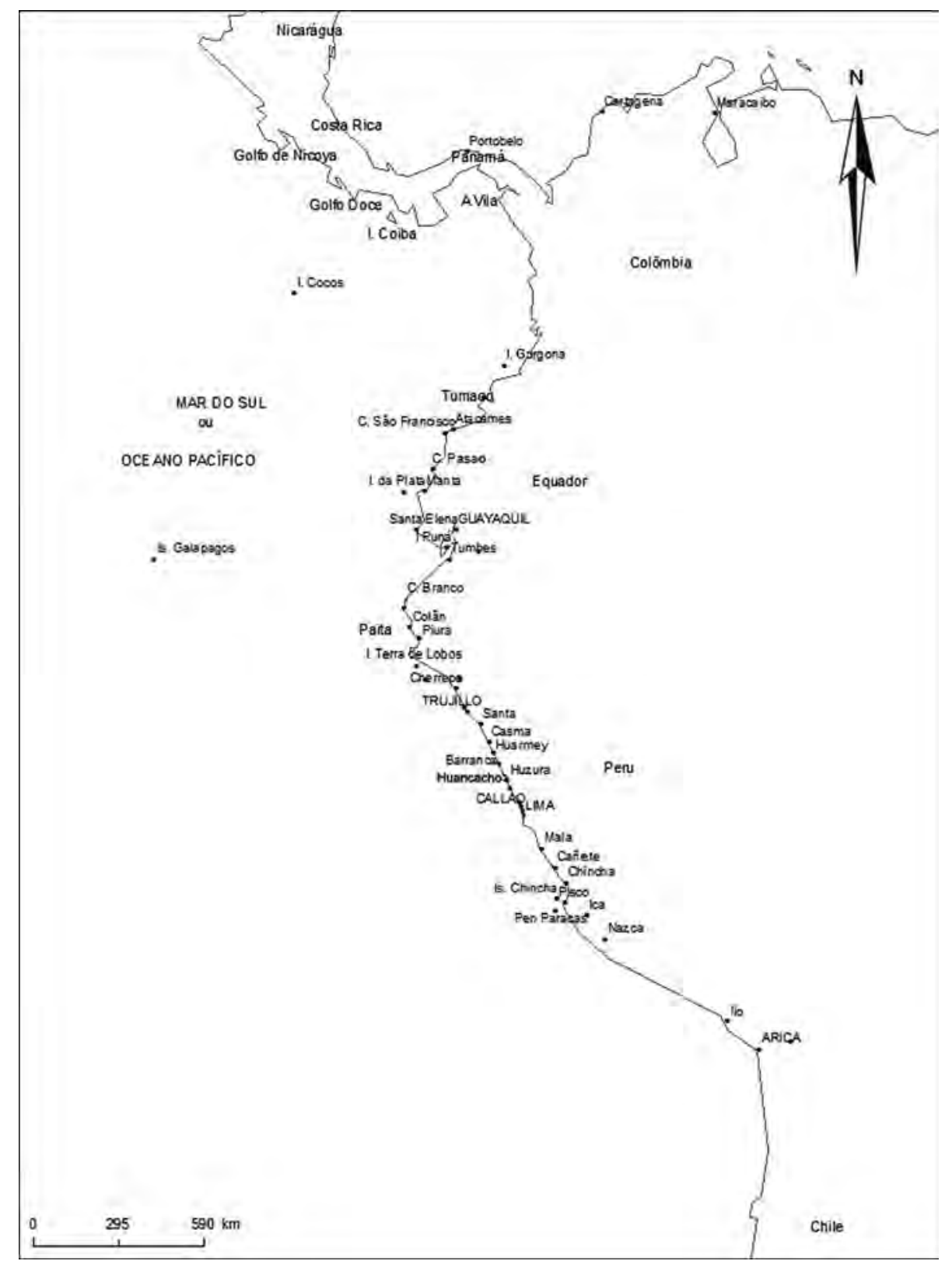

Fig. 9. Escalas dos barcos ingleses e franceses.

Nosso ponto de partida foi o livro Nobiliarquia Paulistana de Pedro Taques, escrito no Brasil em meados do século XVIII. Ao fazer uma parte da história e da genealogia de Francisco Dias Velho, o fundador do assentamento português de Nossa Senhora do Desterro - atual Florianópolis, Ilha de Santa Catarina -, Taques (1953: 85-86) resumiu o inquérito realizado pela justiça portu- guesa em Santos, no dia 26 de fevereiro de 1688 (Livro de Registro n. 4 da Real Fazenda de São Paulo), contra o pirata Thomas Frins, preso na ilha de Santa Catarina, no final de 1687:

1. Thomaz Frins era um pirata inglês, navegando com mais sete ingleses;

2. Frins liderava um patacho; 


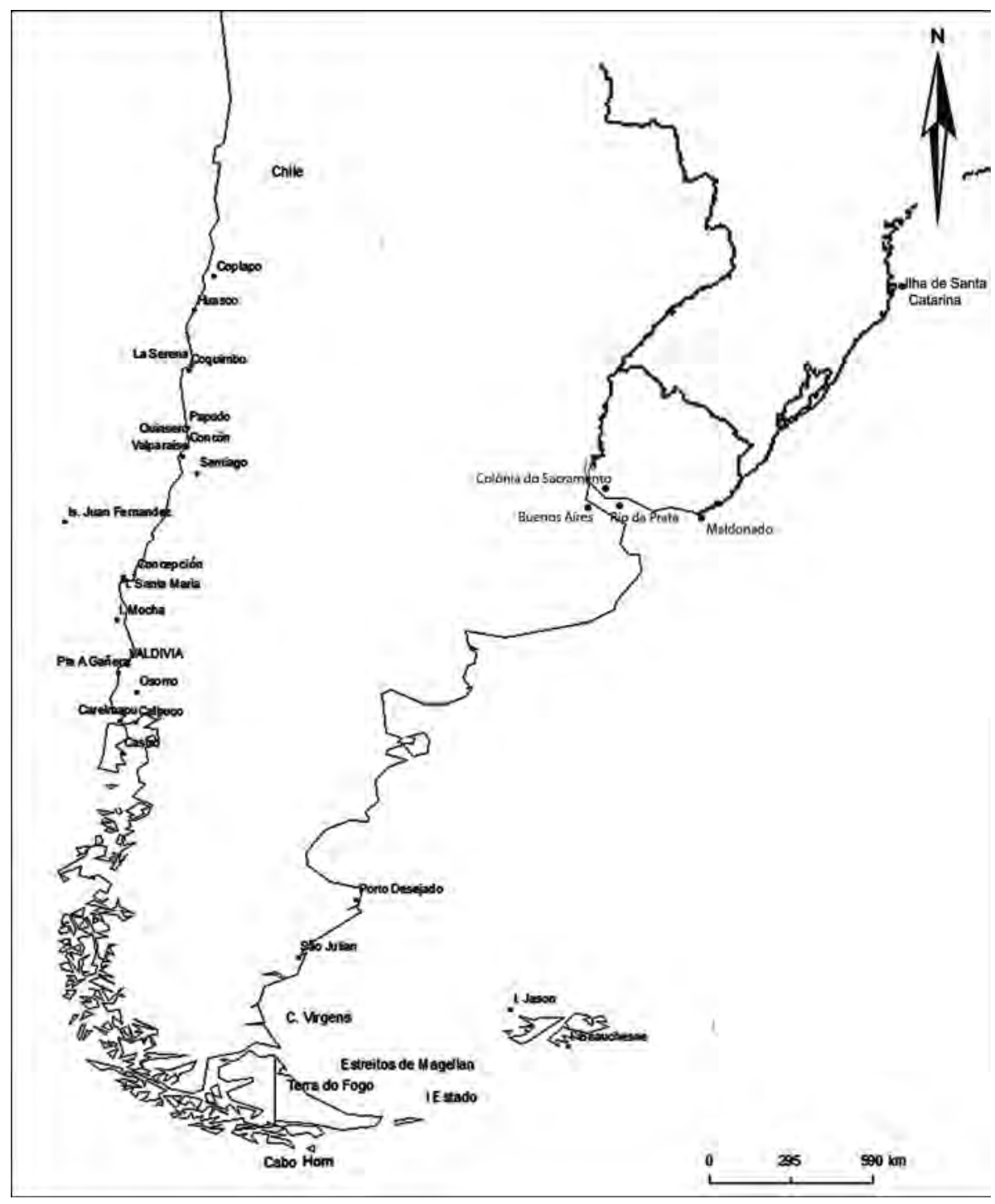

Fig. 10. Escalas dos barcos ingleses.

3. Foi da Inglaterra para Porto Belo, Panamá;

4. Pertencia à frota de navios pequenos e 900 homens, comandados por "Samoloy"; 5. "Andaram como piratas", saqueando as terras da coroa espanhola: Panamá, Callao, "barra da Ponta" $\left(5^{\circ}\right)$, Porto Santo $\left(9^{\circ}\right)$;

6. O barco de Frins separou-se da frota nas imediações de Callao;

7. Ficou "por seis meses" procurando o resto da frota;
8. Guerrearam em Porto Santo, no Pacífico, e "ficaram destruídos", sobrevivendo Frins e sete homens;

9. Necessitando de água e reparos, arribaram à Ilha de Santa Catarina;

10. Foram aprisionados por Francisco Dias Velho em 1687, que inventariou e confiscou a carga, e prendeu a tripulação.

O objetivo seguinte foi identificar a qual frota pirata Frins pertenceu. Com a revisão bibliográfica ficou evidente que era a frota 
liderada por Edward Davis, que chegou a reunir cerca de 1000 homens, a maioria europeus (Noelli, Viana e Moura 2009; Bradley 1999). Dos relatos piratas citados acima, Raveneau de Lussan corroborou Pedro Taques de forma mais completa, enquanto Wafer não foi tão explícito. Lussan (1690: 173) encontrou o barco dos oito ingleses na noite de 12 de abril de 1687, próximo da Ponta de Santa Helena, no Equador ${ }^{4}$ (os colchetes foram inseridos pelo tradutor):

"A gente achou que [o barco] seria uma presa de vinho e milho que o capitão Davis tinha feito quando ela saía de Nazca, e que tinha desgarrado dele. Ele tinha colocado dentro oito ingleses para conduzi-la, que tinham encontro marcado, em caso de separação, na ilha La Plata. Estas pessoas nos contaram que depois que eles nos tinham deixado na ilha de San Juan, ${ }^{5}$ eles haviam feito muitas descidas \paradas em vários lugares, entre os quais Tacna, Arica e Pisco".

Lussan (1690:174) também relatou que os oito ingleses, caso não encontrassem Davis, retornariam para o Oceano Atlântico (Mar do Norte), parando na ilha de Juan Fernandez e contornando o estreito de Magalhães. Um aspecto importante a ressaltar é que Lussan deu vOz aos oito ingleses, apresentando em primeira mão um resumo do que eles lhe contaram.

O relato de Lussan foi confirmado por Wafer (1704:158), companheiro dos oito ingleses e que participou diretamente da ação, relatando sobre "uma barca que nós tiramos de Pisco". Ele datou essa parada em Pisco em julho de 1686,

(4) Texto (mantivemos como está no original de 1690, sem atualizar ou corrigir): “... on trouva que c'étoit une prise de vin $\&$ de bled que Le Capitaine David avoit faite comme elle sortoit de Nasca, \& qui s'étoit efflotée de luy; Il avoit mis dedans huit anglois pour la conduire, qui avoient rendezvous en cas de separation, à l'isle de Plata. Ces gens nous aprirent que depuis qu'ils nous avoient quittez à l'isle Saint Juan, ils avoient fait quantité de descents \& en plusieurs endroits, entr'autres à Sagna, à Arrica \& à Pisca" (5) Lussan (1690:60-67) citou diversas vezes a "Isle Saint Juan Cueblo", atual Isla Coiba, litoral do Panamá, e que a separação entre o seu grupo e E. Davis foi por meados de março de 1686. onde combateram contra os habitantes e "pegaram" uma carga de vinho estocado em "jarras de oito galões cada” (Wafer 1704: 156). Para Wafer, Pisco era um dos portos de Nazca, fazendo uma associação específica entre ambos. Em setembro, a barca apresada, mais o Bachelor's Delight e o barco capitaneado por William Knight rumaram para carenar na Ilha de Juan Fernández, ao largo do Chile (Wafer 1704: 158). Em dezembro Knight foi para o Atlântico, enquanto o Bachelor's Delight e a barca foram para o continente "para costeá-lo de volta, novamente, em direção à Linha do Equador" (Wafer 1704:158; os principais historiadores do tema consideraram que o Bachelor's Delight saiu só de Juan Fernández, mesmo citando Wafer: p. ex.: Burney 1816: 192; Gerhard 1990: 163; Bradley 1999: 484. Arana (2000: 178) foi o único a repetir Wafer sobre os dois barcos que saíram de Juan Fernández).

A principal fonte para esclarecer qual era essa barca é o relato do jesuíta que indicamos acima, disponibilizado pela biblioteca digital Internet Archive (http://archive.org/stream/ noticiasdelsurco00lp\#page/n15/mode/2up). Até o presente é a fonte espanhola mais completa que encontramos, a relatar a sequência das ações do grupo de Davis a partir de julho de 1686. O autor não é linear, mas corrobora e detalha vários aspectos de Taques, Lussan e Wafer, e explica como a tripulação do barco capturado em Pisco ficou reduzida a sete ingleses. Também confirma que eles navegavam sozinhos e que, por fim, desapareceram rumo ao Atlântico. Contudo, consideramos que a sua principal informação é o nome da embarcação, um novo ponto de partida para investigar sua identidade, suas características construtivas, suas atividades econômicas e sua tripulação. Trata-se do impresso de 35 páginas sem numeração, de autor anônimo, com local e data desconhecidos, intitulado Notícias del sur continuadas desde 6 de noviembre de 1686 hasta junio de 1688. Lecrerc (1887: 473) e Toríbio Medina (1904: 168) atribuem a autoria ao padre jesuíta Francisco López y Martínez e a impressão na cidade de Lima. O padre López era, naquele período, confessor do vice-rei Rocaful (Mugaburu 1935: 261). Este texto é complementado 
por outro impresso limenho de mesmo formato gráfico, possivelmente do mesmo autor devido ao estilo da redação, intitulado Últimas notícias del sur, y felices operaciones del navio San Joseph, de la Esquadra de N. Señora de Guía contra piratas (cf. Lecrerc 1887: 473; Toríbio Medina 1904: 168). A raridade de ambos os relatos é a causa de não constar da principal historiografia sobre os ataques piratas ao Vice-Reino do Peru em 1684-1687 (p. ex.: Burney 1816; Arana 2000; Lohman Villena 1975; Gerhard 2003. Bradley 1999, 2009, é uma exceção, usando essa fonte para outros temas).

O texto Notícias del sur declara que a barca foi surpreendida e capturada pelos ingleses de E. Davis em Paita, quando eles atacavam o assentamento peruano. Contudo, outra passagem do mesmo texto possui uma descrição que permite concluir que a barca foi apresada pelo grupo de Davis em Pisco, concordando com os relatos de Lussan e de Wafer. O apresamento teria ocorrido porque a população pisquenha fugiu e não apoiou o barco tripulado por espanhóis. Segundo o autor:

"na chegada de improviso do navio N. Señora de Aránzazu ao porto de Pisco... e, ainda que a sua vinda aumentasse entre os nossos a esperança de maior vitória, foi o motivo de que não a conseguisse inteiramente, como sem dúvida se conseguiria, se não houvessem permanecido todos na vileza da infame fuga" (Notícias del sur). ${ }^{6}$

\section{Como a vinda da Aránzazu teria aumen-} tado a esperança de grande vitória se estivesse sob o domínio dos piratas? O autor também relata que a Aránzazu chegou de improviso, se achou sem ser chamada entre eles, isto é, chegou sem saber que os ingleses estavam em Pisco e ficou cercada de inimigos. Apesar da ambiguidade dessa fonte em relação ao local de apresamento, consideramos que o mais importante é o fato de ela relatar que foi um barco espanhol

(6) Não citamos a referência completa, com ano da publicação e páginas, pois o texto não possui a numeração das páginas. que ficou sob o domínio dos oito ingleses e que o seu nome é Nuestra Señora de Aránzazu.

A próxima citação das Notícias del sur também confirma Taques e Lussan, sobre o barco com poucos tripulantes, explicando a causa da redução da tripulação (os colchetes nas citações foram inseridos pelo tradutor):

“deram notícia que na Ilha de la Plata estavam alguns Ingleses, e saiu em um barco Domingo Villar Tejeda, com apenas vinte soldados; e com grande determinação e valor os rendeu, e recobrado o nosso barco, retornaram para Guayaquil, de onde se remeteram dezessete piratas à Lima, (e entre eles o capitão do navio Nuestra Señora de Aránzazu, que [lá] ficou com apenas sete piratas, e não se viu mais neste mar) onde pagaram com as suas vidas os sacrilégios da sua pirataria”.

A causa da redução foi o combate com os espanhóis, que atacaram os ingleses da N. S. de Aránzazu, matando e prendendo parte dos piratas, que foram levados para interrogatório e execução em Lima. Existe uma discrepância entre as fontes a respeito do lugar do combate. $\mathrm{O}$ autor na Notícia não cita onde, mas indica algum local entre Guayaquil e a ilha da Prata, em uma distância com cerca de 100 km. Lussan encontrou com os oito ingleses nas imediações da Ponta de Santa Helena, mas não menciona o combate que reduziu a sua tripulação. Thomas Frins declarou à justiça portuguesa (Taques 1953: 86) que "na barra da ponta em altura de 5 graus tivera encontro com castelhanos, que lhe mataram muitos homens" - seria próximo de Paita, a cerca de $250 \mathrm{~km}$ de Guayaquil. Mas Taques (1953:86), também menciona que "de um lugar de Porto Santo ficaram destruídos os ingleses em altura de 9 graus da costa do sul, ficando só ele capitão com sete homens em seu navio". Consideramos que o mais importante é a explicação da causa da redução da tripulação para sete ou oito ingleses e que, com a prisão do capitão, pode-se considerar que deve ter sido o momento em que Thomas Frins assumiu a liderança do barco.

O lugar mais exato do combate, conforme María del Pillar Ruiz (1979: 65), parece ser o in- 
dicado pelo testemunho de Bartolomé Sanchez, morador de Guayaquil, aprisionado em 1687 pelos piratas. Segundo Sanchez: a luta foi na entrada da Baía de Guayaquil, "entre El Amortajado e Punta de Arena”, e que os barcos inimigos encurralados foram a "Urca" [Bachelor's Delight] e o "Aránzazu", que conseguiram fugir em dois de junho para a Ilha Puná, na mesma baía. Mas seria possível o Aránzazu ter se engajado para lutar com apenas oito tripulantes? Como eles manobraram o barco e combateram? Será que foi no início de maio, ao invés do início de junho? Parece mais plausível, se Lussan informou corretamente a data de 12 de abril de 1687, que a redução da tripulação da Aránzazu foi antes de maio. As Notícias del sur situam em 23 de abril um combate renhido entre espanhóis e a Urca (Barchelor's Delight) acompanhada por outros barcos. Parece que abril foi o mês do embate e que Bartolomé Sanchez foi mais preciso em relação ao local onde a Aránzazu perdeu a maior parte da tripulação.

As Notícias del sur também informam que a N. S. de Aránzazu, depois da derrota, "não foi mais vista nesse mar". E, complementando as Notícias, o texto Últimas notícias relata que: o "navio Nuestra Señora de Aránzazu, e a [nau] francesa, dos quais se avisa de Amapala, que não foram mais vistos naquela costa, porque, como já se disse, saíram pelo Estreito [Cabo Horn]". Provavelmente, essa nau francesa era o barco onde estava Lussan.

Por fim, a nossa última fonte peruana, por enquanto, é o extenso e truncado memorial de 18 de novembro de 1689, do vice-rei Melchor de Navarra y Rocaful, que confirma que o Aránzazu estava de posse dos "inimigos" piratas (Rocaful 1859: 114). Ele apresenta um resumo sobre o contingente pirata que estava sendo formado para atacar Guayaquil em 1687 e informa o tamanho da tripulação do barco dos oito ingleses antes do ataque espanhol: "o navio Aránzazu, sem artilharia, [é tripulado por] outros 40 ingleses" (Rocaful 1859: 327). Rocaful indica o número mais aproximado do tamanho da tripulação do Aránzazu antes da derrota para os espanhóis. O contexto arqueológico da Praia dos Ingleses também corrobora o vice-rei, sobre o barco não ter artilharia. Rocaful (1859: 327) também confirma Taques e Lussan, quando escreveu que o Aránzazu "anda solto", sozinho.

A passagem dos piratas pelo Cabo Horn é relatada por Wafer, que informa inicialmente sobre a viagem de William Knight em dezembro de 1686 e a sua própria, a bordo do Bachelor's Delight, no natal de 1687 (Wafer 1704: 158, 174). A confirmação de que o Bachelor's parou em Maldonado foi dada por Wafer (1704:177) e corroborada por duas cartas de abril de 1688, de José de Herrera y Sotomayor, governador de Buenos Aires, sobre barcos ingleses vindos do "Mar do Sul" - do Oc. Pacífico (Catálogo 1901: 393; Pastells 1923: 174). O vice-rei Rocaful (1859: 332) recebeu a carta de Sotomayor, confirmando que no rio da Prata se "haviam reconhecido uns navios que depois se soube eram os piratas que saíram deste mar".

O destino de Knight é desconhecido, enquanto que Wafer, Davis e Andrew Hinson da tripulação do Bachelor's Delight retornaram à Virginia, nos Estados Unidos, após costear o Brasil e passar pelas ilhas do Caribe. A justiça inglesa prendeu o grupo no rio James em junho de 1688 , arrestou a preciosa carga saqueada nas colônias espanholas e abriu um processo que durou até o primeiro semestre de 1691. Após diversas manobras e negociações, os piratas conseguiram reaver parte dos seus butins e doar 300 libras, uma fortuna na época, contribuindo para a construção da sede do William and Mary College, em Williansburg, que existe até hoje (Berkeley 1966).

O destino dos oito ingleses do Nuestra Señora de Aránzazu foi a Ilha de Santa Catarina, para reabastecer e descansar no final de 1687. Existe a documentação portuguesa da prisão dos ingleses e o próprio naufrágio na Praia dos Ingleses, para testemunhar o final da sua jornada iniciada no Oceano Pacífico, pela altura da Baía de Guayaquil. Os portugueses da ilha prenderam os oito ingleses e arrestaram a carga. Como verificamos no contexto arqueológico, o barco continha basicamente artefatos usuais do cotidiano e nenhum vestígio de riqueza. Pedro Taques (1953:85-86) resumiu assim os eventos: na ilha de Santa Catarina, "em 1687 entrou um patacho inglês de arribada, cujo capitão era Thomas Frins e pirata: o capitão mor Francisco 
Dias foi a bordo, prendeu a este capitão e os mais ingleses"; Francisco Dias Velho mandou "inventariar toda a fazenda, que se achava em dito navio, que constava do mesmo inventário que havia remetido com ele [o] capitão e seus companheiros" para Santos em fevereiro de 1688, e que "este grande cabedal ficou à R. F. [Real Fazenda]".

Após o depoimento de Frins e seus companheiros em Santos, é provável que a justiça tenha liberado-os após um período na prisão, uma vez que eles não haviam perpetrado nenhum crime no Brasil. Mas é certo que formaram um novo grupo de assalto, pois em 1689, provavelmente no segundo semestre, retornaram à Ilha de Santa Catarina para vingar-se de Francisco Dias Velho. Conforme Taques (1953:86), os piratas "voltaram sobre a mesma ilha armados com força de gente e lhe tiraram a vida". Posteriormente, no dia dois de novembro de 1689, na vila de São Paulo, foi lavrado o inventário dos bens de Dias Velho, por "sua morte e falecimento" (Boiteux 1931: 467).

O governador do Rio de Janeiro, Francisco Naper de Lencastre, em carta do dia 30 maio de 1690, deu notícia ao rei de Portugal que "andava um navio de piratas nesta costa e havia feito dano nela", antes de fevereiro, referindo-se ao ano de 1689 (Lencastre 1957: 524). Esta carta abre caminho para novas pesquisas de arquivo sobre esses piratas e que poderão confirmar se se trata de Frins e seu grupo.

\section{Palavras finais e novos pontos de partida}

Para concluir, é importante destacar que existem várias fontes históricas para ampliar o conhecimento sobre o barco naufragado na Praia dos Ingleses, sua tripulação e sua história antes da captura pelos piratas ingleses; além de aumentar o conhecimento sobre as ações do grupo de Thomas Frins na costa brasileira e no colapso do assentamento português da ilha de Santa Catarina. Para alcançá-las, será necessário ir aos arquivos do Brasil, Portugal, Chile, Peru, Equador, Colômbia, Panamá, Costa Rica, Guatemala, México, Jamaica, Espanha, Inglaterra e Estados Unidos.
Também merecem destaque os novos dados sobre a identidade do naufrágio da Praia dos Ingleses, o Nuestra Señora de Aránzazu. Os portugueses de Santos classificaram-no como um patacho, uma definição muito aberta em relação às dimensões e a armação. O livro de Wafer trata-o como uma barca, outra definição que não permite uma percepção conclusiva. Porém, as fontes espanholas, como vimos, relataram tratar-se de um "navio", conceito igualmente aberto, mas que permite conceber um barco com dimensões maiores de 20 metros, corroboradas pelo leme de 6,7 metros de altura que encontramos no sítio arqueológico. Pode ser que os arquivos equatorianos sobre a construção naval na baía de Guayaquil reservem boas surpresas e mais descobertas interessantes no futuro.

Finalizamos, mencionando que outros barcos atuando no Oceano Pacífico daquele período também eram batizados como Aránzazu, em homenagem à santa cultuada no País Basco. Portanto, o barco de Frins não é o mesmo Nuestra Señora de Aránzazu y el Sacramento, de propriedade de Gabriel Escalante, presente no informe de 15 de agosto de 1695, sobre as embarcações existentes em águas peruanas, mandado fazer pelo vice-rei Conde de Monclova (Lohmann Villena 1975: 234; Clayton 1978: 177). Também não é o Nuestra Señora de Aránzazu y San Ignácio, capturado pelo Cygnet, em 4 de março de 1687, perto da baía de Manila, nas Filipinas (Lázaro 2011: 34).

\section{Agradecimentos}

À FAPESC, pelos recursos para o projeto. À Marinha do Brasil, pelo apoio e avaliação rigorosa. Ao Prof. Kay Saalfeld, do Laboratório Invertebrados Marinhos \do Departamento de Ecologia e Zoologia da Universidade Federal de Santa Catarina, pela orientação na análise das conchas. Para Célia Bonhome, pela tradução do francês. Para Lúcio Menezes Ferreira, Fabíola Andréa Silva e Jorge Ortiz Sotelo, pelas várias ideias e sugestões e, principalmente, para nosso grande parceiro e enciclopédia sobre Santa Catarina colonial, Amílcar D’Ávila de Mello. 
NOELLI, F.S.; MONTEIRO, P.C.; VIANA, A. Praia dos Ingleses 1: Underwater Archaeology at Santa Catarina Island, Brazil (Part 2). R. Museu Arq. Etn., São Paulo, 21: 293-314, 2011

Abstract: This work is a second part of the article published by Revista do Museu de Arqueologia e Etnologia (Noelli, Viana, Moura 2009), where we presented: 1) the methodology applied in underwater archeology excavation of a shipwreck on the Praia dos Ingleses, Island of Santa Catarina, Brazil; 2) the first results of the data analysis; 3) the historical research on the wreck context and the identification of the vessel. Now we will present the data that support the hypothesis tested in 2009: that the researched boat was the one which the historical sources indicated be sailed by Thomas Frins and seven englishmen accused of piracy in the Viceroyalty of Peru (1687) and Brazil (1688).

Keywords: Underwater Archaeology - Maritime History - Colonial Brazil.

\section{Referências bibliográficas}

ABBOTT, R.

1974 American seashells: the marine mollusca of the Atlantic and Pacific coasts of North America. New York: Van Nostrand Reinhold.

ABBOTT, R.; DANCE, S.

1990 Compendium of seashells: a color guide to more than 4,200 of the world's marine shells. Bathurst: Crawford House.

ARANA, D. B.

2000 Historia general de Chile, v. 5. Santiago de Chile: Editorial Universitária.

\section{BERKELEY, E.}

1966 Three philanthropic pirates. The Virginia Magazine of History and Biography, 74 (4): 433- 444.

BOITEUX, L.A.

1931 Paulistas em Santa Catarina seiscentista. Annaes do Museu Paulista, 4: 428-479.

\section{BRADLEY, P.T.}

1999 British maritime enterprise in the New World: from the late fifteenth to the mid eighteenth century. Studies in British History, v. 57. Lewiston: Edwin Mellen Press.

2009 Spain and the defence of Peru, 1579-1700. Royal reluctance and colonial self-reliance. Raleigh: Lulu Press.

BURGER, R. L.

2008 Chavín de Huantar and its sphere of influence. In: Silverman, H.; Isbell, W.H.
(Eds.) Handbook of South American Archaeology. New York: Springer: 681-703.

BURNEY, J.

1816 History of the buccaneers of America. London: Luke Hansard \& Sons.

CABREDO, M.T.

1999 El modo de vida marítima en el occidente de México. Revista de Arqueología Americana, 16: 183-192.

CATIE-UICN

1990 Wise use of the mangrove resources in Estero Real, Nicarágua and Térraba-Sierpe, Costa Rica: A proposal submitted by CATIE $\backslash I U C N$ to DANIDA. S.l., S. E.

CLAYTON, L. A.

1978 Los astilleros de Guayaquil colonial. Guayaquil: Archivo Nacional de Guayas.

CATÁlOGO

1901 Catálogo de documentos del Archivo de Indias en Sevilla, referentes a la historia de la República argentina 1514-1810. Buenos Aires: Ministério de Relaciones Exteriores. p. 393.

COE, M.D.; FLANNERY, K.V.

1967 Early cultures and human ecology in South Coastal Guatemala. Washington, D.C.: Smithsonian Institution.

CONCHA, M.

1871 Crónica de La Serena, desde su fundación 
hasta nuestros días 1549-1870. Serena: Imprenta de "La Reforma".

COOKE, R.

2001 Gran Coclé. In: Peregrine, P.; Ember, M. (Eds.) Encyclopedia of Prehistory, 5: 197-203.

DAMPIER, W.

1702 A new voyage round the world. $2^{\text {nd }}$ ed., vol. 1. London: James Knapton.

EICHHORST, T.

2010 Neritopsine Gastropods. Taxon Pages. Clypeolum latissimum (Broderip, 1833). Disponível em: <http://neritopsine. lifedesks.org/pages/562>. Acesso em 15 outubro 2010.

GBIF

Global Biodiversity Information Facility: Data Portal. Disponivel em: http://data.gbif. org/welcome.htm

FLMNH

Florida Museum of Natural History: Invertebrate Zoology Malacology Databases. Disponível em: http://www.flmnh.ufl. edu/databases/

GERHARD, P.

1990 Pirates of the Pacific 1575-1742. Lincoln: University of Nebraska Press.

2003 Pirates of New Spain, 1575-1742. New York: Courier Dover Publications.

GUZMÁN, N.; SAÁ, S.; ORTLIEB, L.

1998 Catálogo descriptivo de los moluscos litorales (Gastropoda y Pelecypoda) de La Zona de Antofagasta, $23^{\circ} \mathrm{S}$ (Chile). Estudios Oceanológicos, 17: 17-86.

IABIN

Inter-American Biodiversity Information Network: Species \& Specimen Data. Disponível em: http://www.iabin.net/

KEEN, A.M.

2006 Sea shells of tropical west America: marine mollusks from Baja California to Peru. Stanford: Stanford University Press.

LACERDA, L.D. (Ed.)

2001 Mangrove ecosystem: function and management. New York: Springer.

LÁZARO, F.L.

2011 The Misfortunes of Alonso Ramirez: The True Adventures of a Spanish American with seventeenth-century pirates. Austin: University of Texas Press.

LANE, $\mathrm{K}$.

1999 Blood and silver. A history of piracy in the Caribbean and Central America. Oxford: Signal Books.
LECRERC, C.

1887 Bibliotheca Americana: Histoire, géographie, voyages, archéologie et linguistique des deux Amériques et des Iles Philippines. Paris: Maisounneuve \& Cie.

LENCASTRE, F.N.

1957 D. Francisco Naper de Lencastre a S. M. Rio de Janeiro, 30 de maio de 1690. In: Ferrand de Almeida, L. A diplomacia portuguesa e os limites meridionais do Brasil. Coimbra: Faculdade de Letras da Universidade de Coimbra. v. 1: 523-525.

MANNINO, M.A.; THOMAS, K.D.

2002 Depletion of a Resource? The impact of Prehistoric human foraging on intertidal mollusk communities and its significance for human settlement, mobility and dispersal. World Archaeology, 33 (3): 452-474.

MASUCCI, M.A.

1995 Marine Shell Bead Production and the Role of Domestic Craft Activities in the Economy of the Guangala Phase, Southwest Ecuador. Latin American Antiquity, 6 (1): 70-84.

MCGIMSEY, C.R.

1956 Cerro Mangote: A Preceramic site in Panama. American Antiquity, 22 (2): 151-161.

MEGGERS, B.J.; EVANS, C.; ESTRADA, E.

1965 Early Formative Period of Coastal Ecuador. Washington D.C.: Smithsonian Institution.

MIRANDA-BAEZA, A.; VOLTOLINA, D.; CORDERO-ESQUIVEL, B.

2006 Filtration and clearance rates of Anadara grandis juveniles (Pelecypoda, Arcidae) with different temperatures and suspended matter concentrations. Revista de Biología Tropical, 54 (3): 787-792.

MOORE, J.D.

1991 Cultural responses to environmental catastrophes: Post-El Niño subsistence on the Prehistoric North Coast of Peru. Latin American Antiquity, 2 (1): 27-47.

MOORE, J.D.; MACKEY, C.J.

2008 The Chimú Empire. In: Silverman, H.; Isbell, W.H. (Eds.) Handbook of South American Archaeology. New York, Springer: 783-807.

MUGABURU, J.; MUGABURU, F.

1935 Diario de Lima (1640-1694). Crónica de la época colonial. Vol. 2. Lima: Imp. C. Vazques.

NOELLI, F.; VIANA, A.; MOURA, M.L.

2009 Praia dos Ingleses 1: Arqueologia Suba- 
quática na Ilha de Santa Catarina. Revista do Museu de Arqueologia e Etnologia. São Paulo, 19: 179-203.

ODRIOZOLA, M.

1865 Colección de documentos literarios del Peru. V. 2. Lima: Aurello Alfaro.

OLSSON, A.

1961 Mollusks of the Tropical Eastern Pacific, particularly from the southern half of the Panamic-Pacific faunal province (Panamá to Peru). Panamic-Pacific Pelecypoda. Ithaca: Paleontological Research Institution.

PAULSEN, A.C.

1974 The thorny oyster and the voice of God: Spondylus and Strombus in Andean Prehistory. American Antiquity, 39 (4): 597-607.

RICHARDSON, J.B.

1998 Looking in the right places: Pre-5000 B.P. maritime adaptations in Peru and the changing environment. Revista de Arqueología Americana, 15: 33-56.

ROCAFUL, M.N.

1859 Memoria de los virreyes que han gobernado el Perú, durante el tiempo del coloniaje español. Vol. 2. Lima: Librería Central de Felipe Bailly.

RUIZ, M.P.

1979 La toma del Puerto de Guayaquil en 1687. Sevilla: Escuela de Estudios Hispano-Americanos de Sevilla.

SAPIR, O.L.

1968 Cultural chronology of the Gulf of Chiriqui, Panama. Washington, D.C.: Smithsonian Institution.

SARMA, A.V.N.

1974 Holocene Paleoecology of South Coastal Ecuador. Proceedings of American Philosophical Society, 118 (1): 93-134.

SCHWENGEL, J.

1938 Zoological results of the George Vanderbilt
South Pacific Expedition, 1937. Part I: Galapagos Mollusca. Proceedings of the Academy of Natural Sciences of Philadelphia, 90: 1-3.

SEVEREYN, H.J.; SEVEREYN, Y.G.; EWALD, J.J.

1994 Taxonomic revision of Polymesoda solida (Philipi, 1846) (Bivalvia:Corbiculidae), a new name for Polymesoda arctata, the estuarine clam of Lake Maracaibo and other estuaries of the tropical Atlantic coasts of America. Ciencia, 2 (2): 53-65.

STAHL, P.

2003 The zooarchaeological record from Formative Ecuador. In: Raymond, J.S.; Burger, R.L. (Eds.) Archaeology Formative Ecuador. Washington, D. C., Dunbarton Oaks Research Library: 175-212.

TAQUES, P.

1953 Nobiliarquia paulistana histórica e genealógica. Vol. 2. São Paulo: Livraria Martins.

TORÍBIO MEDINA, J.

1904 La imprenta en Lima (1584-1824). Vol. 2. Santiago: Casa del Autor.

VALDEZ, F.

2008 Inter-zonal relationship in Ecuador. In: Silverman, H.; Isbell, W.H. (Eds.) Handbook of South American Archaeology. New York, Springer: 865-888.

VELIZ, D.; VÁSQUEZ, J.A.

2000 La Família Trochidade (Mollusca: Gastropoda) en el norte de Chile: consideraciones ecológicas y taxonômicas. Revista Chilena de História Natural, 73: 757-769.

VOOHIES, B.; KENNETH, D.J.; JONES, J.G.; WAKE, T.A.

2002 A Middle Archaic Archaeological Site on the West Coast of Mexico. Latin American Antiquity, 13 (2): 179-200.

WAFER, L.

1704 A New Voyage and description of the Isth mus of America. $2^{\text {nd }}$ ed. London: James Knapton. 